\title{
Exploiting Cork as Biosorbent Extraction Phase for Solid-Phase Microextraction to Determine 3-(4-Methylbenzylidene)camphor and 2-Ethylhexyl 4-(Dimethylamino)benzoate in River Water by Gas Chromatography-Mass Spectrometry
}

\author{
Ana C. Silva, Adriana N. Dias and Eduardo Carasek* \\ Departamento de Química, Universidade Federal de Santa Catarina, \\ 88040-900 Florianópolis-SC, Brazil
}

\begin{abstract}
In this study, a method for the determination of 3-(4-methylbenzylidene)camphor (4-MBC) and 2-ethylhexyl 4-(dimethylamino)benzoate (OD-PABA) in river water samples employing cork as the SPME (solid-phase microextraction) fiber was developed. The extraction parameters optimized were $\mathrm{pH}$, ionic strength and extraction time and temperature. For the extraction step, the sample $\mathrm{pH}$ was studied in univariate experiments while the extraction time, temperature and ionic strength were evaluated using a central composite design. The optimal extraction conditions were sample $\mathrm{pH} 4.0$, extraction time $70 \mathrm{~min}$, sample temperature $80{ }^{\circ} \mathrm{C}$ and sodium chloride concentration $6 \%\left(\mathrm{~m} \mathrm{v}^{-1}\right)$. The limits of quantification for 4-MBC and OD-PABA were 0.1 and $0.01 \mu \mathrm{g} \mathrm{L}{ }^{-1}$, respectively. The linear correlation coefficients were greater than 0.97 for both analytes and the developed method showed recovery values between 67 and 107\%. In an evaluation of the fiber-to-fiber reproducibility (fibers produced by different analysts), the relative standard deviation (RSD) was lower than $11 \%(\mathrm{n}=6)$.
\end{abstract}

Keywords: SPME, cork fiber, ultraviolet filters, river water samples, gas chromatographymass spectrometry

\section{Introduction}

Daily exposure to sunlight can have harmful effects on health such as photo-aging, skin cancer and damage to the skin's immunological system. So, the harmful effect of UV radiation on the skin has led to the development of organic chemicals known as UV filters. The use of sunscreens and other personal care products with UV filters may prevent or minimize the harmful effects of solar radiation to the human skin because these filters absorb the UV light. ${ }^{1-3}$

In recent decades, interest regarding the determination of levels of ultraviolet filters in environmental samples has increased considerably due to their presence in aquatic environment. Direct action, such as swimming in and sunbathing beside rivers, as well as indirect actions such as showering and washing clothes, can lead to the input of these compounds to the aquatic environment. ${ }^{2}$

Several studies have shown the negative impact of the presence of these compounds in aquatic ecosystems even at low concentration levels. ${ }^{4,5}$ This is probably due to estrogenic activity from UV filters. ${ }^{6}$ Furthermore,

*e-mail: eduardo.carasek@ufsc.br
UV filters are lipophilic compounds and therefore, they can bioaccumulate and biomagnify through the food chain. ${ }^{7}$ Although there are no regulations that control the residues of these compounds in environmental samples, ultraviolet filters have been cataloged as emergent contaminants, and therefore, the development of analytical methods for determination of UV filters is very important. ${ }^{8}$

Prior to chromatographic analysis, a sample preparation technique is used to remove or reduce potential interferents from the matrix and also to concentrate the analytes. Different sample preparation techniques have been employed for the determination of ultraviolet filters in water samples, such as ultrasound-assisted emulsification microextraction (USAEME), ${ }^{7}$ dispersive liquid-liquid microextraction (DLLME), ${ }^{9-11}$ stir-bar sorptive-extraction (SBSE), ${ }^{12}$ stir-bar sorptive-dispersive microextraction $(\mathrm{SBSD} \mu \mathrm{E}),^{13,14} \mathrm{bar}$ adsorptive microextraction $(\mathrm{BA} \mu \mathrm{E})^{3}$ and solid-phase microextraction (SPME)..$^{15-17}$

In this study, cork fiber was proposed for use in the determination of two ultraviolet filters in river water samples, 3-(4-methylbenzylidene)camphor and 2-ethylhexyl 4-(dimethylamino)benzoate, which are from different 
classes, that are, a camphor and a para-aminobenzoic acid derivative, respectively..$^{18}$ According to reports from literature, these two compounds are commonly found in water samples. ${ }^{6}$

Cork has showed good sorption performance with regard to polycyclic aromatic hydrocarbons and organochlorine pesticides using the SPME technique and it has also produced good results for the extraction of parabens, benzophenone and triclocarban using the $\mathrm{BA} \mu \mathrm{E}$ technique. ${ }^{3,19,20}$ According to previous studies, when cork is thermally treated, its surface is constituted by lignin and suberin, conferring to cork the possibility of making different chemical interactions with organic compounds, in addition, a physical interaction of adsorption is possible due to the porous structure of this sorbent coating. ${ }^{21,22}$ These promising results have prompted the need for new studies on the cork extraction capacity in microextraction procedures, considering that this material is of natural origin and is renewable and biodegradable.

\section{Experimental}

\section{Reagents, materials and solutions}

Analytical standards of 3-(4-methylbenzylidene) camphor (4-MBC) $(98.5 \%$, Fluka) and 2-ethylhexyl 4-(dimethylamino)benzoate (OD-PABA) (98\%, Sigma) were purchased from Sigma-Aldrich Brazil. The standard solutions were prepared in methanol supplied by JT Baker (Mallinckrodt, NJ, USA). Initially, stock solutions of $1000 \mathrm{mg} \mathrm{L}^{-1}$ for each analyte were prepared, and working standard mixtures were subsequently prepared from the stock solutions. Hydrochloric acid, sodium hydroxide and sodium chloride were purchased from Vetec (Rio de Janeiro, Brazil). Aqueous solutions of hydrochloric acid $\left(5 \% \mathrm{~m} \mathrm{v}^{-1}\right)$, sodium hydroxide $\left(1 \mathrm{~mol} \mathrm{~L}^{-1}\right)$ and sodium chloride ( 0 to $30 \% \mathrm{~m} \mathrm{v}^{-1}$ ) were used for $\mathrm{pH}$ adjustments and studies on the ionic strength, respectively. The water used in the experiments was purified in an ultrapure water system (Mega Purity, Billerica, USA). The cork fibers were prepared with cork powder ( $\geq 200 \mathrm{mesh}$ ), araldite (10 min) epoxy glue (Brascola, São Bernardo do Campo, Brazil) and Waterproof 15 (Carborundum, Rio de Janeiro, Brazil).

\section{Instrumentation and chromatographic conditions}

In this study, a Shimadzu GC-MS QP2010 Plus gas chromatograph, equipped with a split/splitless injector, a mass spectrometer detector and a Zebron ZB-5MS (5\% diphenyl-95\% dimethylpolysiloxane) capillary column $(30 \mathrm{~m} \times 0.25 \mathrm{~mm} \times 0.25 \mu \mathrm{m})$, was used for the GC separation (Torrance, USA). The injection was performed in the splitless mode, the injector temperature was $260^{\circ} \mathrm{C}$ and the DI-SPME (direct immersion mode) desorption time was $10 \mathrm{~min}$. Helium was used as the carrier gas at a flow rate of $1.2 \mathrm{~mL} \mathrm{~min}^{-1}$. The column oven temperature program was $110^{\circ} \mathrm{C}(1 \mathrm{~min})$ and was raised at $6{ }^{\circ} \mathrm{C} \mathrm{min}^{-1}$ to $300{ }^{\circ} \mathrm{C}(10 \mathrm{~min})$. The mass spectrometer was operated in the electron impact (EI) ion source mode at $70 \mathrm{eV}$. The transfer line and the ion source temperatures were set at 280 and $250^{\circ} \mathrm{C}$, respectively. The solvent cut time was $15 \mathrm{~min}$. In the optimization of the extraction procedure, the GC-MS equipment was operated in scan mode $(\mathrm{m} / \mathrm{z} 35$ to 400$)$. The analytical figures of merit and the analysis of the samples was carried out in the selective ion monitoring (SIM) mode: 4-MBC $m / z, 211,239$ and 254 (ion for quantification) and OD-PABA $m / z, 148,277$ and 165 (ion for quantification).

The SPME extractions were carried out in a thermostatic bath (Lab Companion RW 0525G, Seoul, Korea) for temperature stabilization with a magnetic stirrer for sample agitation. A heating block (Dist - Indústria e Comércio de Equipamentos para Laboratórios Ltda., Florianópolis, Brazil) was used for the preparation of the SPME fibers. The $\mathrm{pH}$ adjustments were performed with a pHmeter (Digimed, São Paulo, Brazil).

\section{Preparation of the cork fibers}

The SPME fibers were prepared from the cork stoppers of wine bottles as previously described. ${ }^{19,20}$ The cork powder ( $\geq 200$ mesh) was immobilized with epoxy glue on NiTi wires with $2 \mathrm{~cm}$ length and $0.2 \mathrm{~mm}$ thickness. The fibers were then placed into a heating block at $180^{\circ} \mathrm{C}$ and kept there for $90 \mathrm{~min}$. After this time, the fibers were withdrawn and left to cool to ambient temperature. The fibers were then conditioned at $260{ }^{\circ} \mathrm{C}$ for $60 \mathrm{~min}$ in the $\mathrm{GC}$ injection port. In addition, to determine the fiber-to-fiber reproducibility, fibers were prepared by two different analysts.

\section{Optimization of the SPME procedure}

The SPME was carried out in direct-immersion extraction mode and the extraction parameters $\mathrm{pH}$, ionic strength, extraction time and temperature were studied. The sample $\mathrm{pH}$ was evaluated using the univariate procedure and the other parameters employing a central composite design. The sample $\mathrm{pH}$ was studied at values of 4, 6 and 8. Ionic strength (0 to $30 \%$ ), extraction time (33 to $117 \mathrm{~min}$ ) and temperature $\left(16\right.$ to $\left.80^{\circ} \mathrm{C}\right)$ were evaluated simultaneously in a central composite design totalizing 17 experiments. The geometric mean of the peak areas obtained for the analytes was used as the response in the StatSoft Statistica 8.0 
computer program. A concentration of $10 \mu \mathrm{g} \mathrm{L}-1$ for $4-\mathrm{MBC}$ and OD-PABA was employed for the optimization study.

\section{Analytical parameters of merit}

The validation parameters determined in this study were the limits of detection (LOD) and quantification (LOQ), linear working range and linear correlation coefficient $\left(\mathrm{r}^{2}\right)$, and precision and recovery assays were carried out. The LOD and LOQ values were determined applying a method based on the parameters of the calibration curve. LOD was considered as the deviation from the linear coefficient equation divided by the slope of the calibration curve following by multiplication by 3.3. LOQ was determined in a similar way, but the final multiplication was by 10 . To determine the LOD and LOQ values, calibration curves in the linear ranges of 0.01 to $0.5 \mu \mathrm{g} \mathrm{L}^{-1}$ for $4-\mathrm{MBC}$ and 0.001 to $0.05 \mu \mathrm{g} \mathrm{L}^{-1}$ for OD-PABA were initially obtained. The recovery assays were carried out at two concentration levels, i.e., LOQ and a higher concentration for each analyte. The precision and recovery assays were carried out with river water samples collected from the Quiriri River, in the city of Joinville, Santa Catarina State, Brazil. These samples were stored in glass bottles, properly sealed and stored in a refrigerator at $4{ }^{\circ} \mathrm{C}$ until analysis.

\section{Extraction efficiency - comparison of cork fiber with PDMS and PDMS/DVB fibers}

The efficiency of the cork fiber for the extraction of 4-MBC and OD-PABA from water samples was compared with those of commercial PDMS/DVB (polydimethylsiloxane/divinylbenzene) and PDMS (polydimethylsiloxane) fibers. These experiments were carried out under the optimized conditions for DI-SPME (extraction time $70 \mathrm{~min}$, extraction temperature $80^{\circ} \mathrm{C}, 9 \%$ $\left(\mathrm{m} \mathrm{v}^{-1}\right) \mathrm{NaCl}$ and sample $\left.\mathrm{pH} 4\right)$.

\section{Results and Discussion}

\section{Fiber-to-fiber reproducibility}

The fiber-to-fiber reproducibility has already been evaluated (using five fibers) in a previous study reported by our research group. In this case, the same manufacturing methodology was applied and satisfactory results (RSD $\leq 18.6 \%$, relative standard deviation) were obtained..$^{19}$ In addition, the scanning electron microscopy to evaluate the surface of the proposed fiber has previously been carried out, ${ }^{19}$ these results showed a porous and rough surface, which is particularly interesting to enhance the physical sorption of the analytes by the sorbent phase. Two cork fibers were prepared, each by a different analyst, and the fiber-to-fiber reproducibility was evaluated. The preparation of the cork fibers was manual but, interestingly, the two different analysts produced similar fibers, with the RSD value being lower than $11 \%(\mathrm{n}=3$ each analyst) (Figure 1). The fibers were used for 50 extraction/desorption cycles with no decrease in their performance. The carryover effect was evaluated with experiments of the blank fiber and of the blank sample at the beginning of the day, and carryover effect was not observed. According to analysis of variance (ANOVA) tables, it is possible to observe that the results have not exhibited statistical differences because of the $F$ calculated for 4-MBC and OD-PABA were lower than $F$-critic values, this information is contained in the Supplementary Information (SI section) (Figures S1 and S2). Therefore, the proposed fibers exhibited very satisfactory reproducibility.

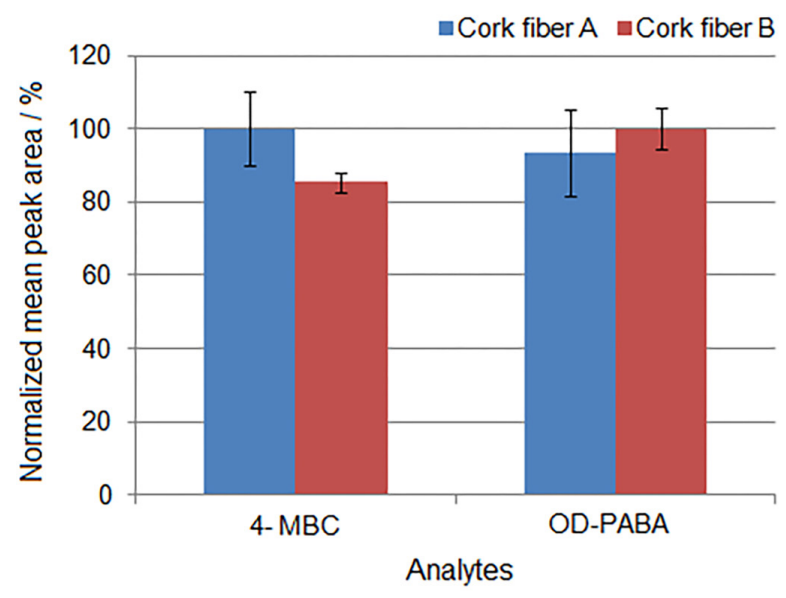

Figure 1. Evaluation of the fiber-to-fiber reproducibility, cork fiber A (fiber produced by analyst A) and cork fiber B (fiber produced by analyst B). DI-SPME conditions: spiked level $10 \mu \mathrm{g} \mathrm{L}^{-1}$, extraction time $40 \mathrm{~min}$, extraction temperature $80^{\circ} \mathrm{C}, 9 \% \mathrm{NaCl}$ and 3 replicates for each analyst.

\section{Optimization of the $\mathrm{pH}$ solution}

According to previous studies described in the literature, the extraction efficiency of OD-PABA is better at acidic $\mathrm{pH}$ (as $\mathrm{pH} 4$ ). At higher $\mathrm{pH}$ values, a reduction in the extraction is observed due to the hydrolysis of this compound..$^{9,14}$ Although, 4-MBC is not ionizable and, theoretically, a variation in the hydrogen potential should not affect it, studies using acid $\mathrm{pH}$ values show better results for this target. ${ }^{9,14}$ In the procedure proposed herein, a $\mathrm{pH}$ of 4 showed the best extraction efficiency, as seen in Figure 2.

\section{Multivariate optimization}

Based on the central composite design (Figure 3), the optimal extraction conditions were defined as $70 \mathrm{~min}$ of extraction at $80{ }^{\circ} \mathrm{C}$ and a sodium chloride concentration 


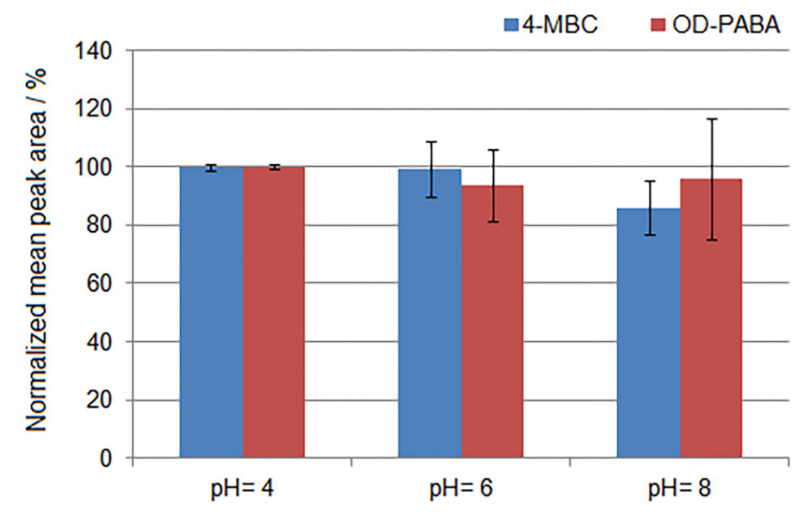

Figure 2. Column chart obtained for the determination of optimum sample pH. DI-SPME conditions: spiked level $10 \mu \mathrm{g} \mathrm{L}^{-1}$, extraction time $40 \mathrm{~min}$, extraction temperature $60^{\circ} \mathrm{C}$, without the addition of salt and 3 replicates.

of $6 \%\left(\mathrm{~m} \mathrm{v}^{-1}\right)$. According to the $\log \mathrm{K}_{\mathrm{OW}}$ values, 4-MBC $\left(\log \mathrm{K}_{\mathrm{OW}}=4.95\right)$ has a more polar character than OD-PABA $\left(\log \mathrm{K}_{\mathrm{OW}}=5.412\right)$. The surface of the 4-MBC exhibited better results (not shown) with a salt concentration between 10 and $15 \%$, and for OD-PABA the surface showed better extraction efficiency (results not shown) at a salt concentration between 0 and $6 \%$. These results can be explained by the difference in the polarities of 4-MBC and OD-PABA. Therefore, as a compromise condition for the two analytes, a concentration of $6 \%\left(\mathrm{~m} \mathrm{v}^{-1}\right)$ of sodium chloride was used. The higher temperature $\left(80^{\circ} \mathrm{C}\right)$ was defined for subsequent tests since, in the direct-immersion extraction mode, an increase in temperature usually favors the diffusion of the analytes in the extractor phase. According to the findings of other studies, cork fiber presents good results with an extraction time higher than $60 \mathrm{~min}$ in the extraction of semi-volatile compounds by DI-SPME..$^{19,20}$

\section{Analytical figures of merit}

This study showed good results for the LOD, LOQ values, linear range and correlation coefficient, as shown in Table 1 . The recovery assay results were acceptable and recovery ranged between 67 and $117 \%$, with good precision
(RSD $\leq 18 \%$ ), as can be seen in Table 2 . Figure 4 shows the chromatograms for the determination of 4-MBC and OD-PABA extracted from spiked and non-spiked river water samples using the cork fiber. In Table 3, the linear range of the proposed method is compared with those obtained in other studies reported in the literature and the method provided a similar or better linear range. The method employing cork fiber is slower, but it does not require the use of solvents and the extractor is a renewal and natural product. Moreover, the proposed method involves less sample handling.

\section{Extraction efficiency - comparison between cork fiber and PDMS/DVB and PDMS fibers}

The extraction efficiency of the cork fiber for the extraction of 4-MBC and OD-PABA from water samples was compared with those of commercial PDMS/DVB and PDMS fibers and the cork fiber provided better results (Figure 5). This finding can be explained by various factors. As described in the literature, cork demonstrates good sorption for compounds with $\log \mathrm{K}_{\mathrm{OW}}>4$. Moreover, cork fiber interacts with compounds through $\pi-\pi$, dipole-dipole and hydrogen bond interactions.

\section{Conclusions}

The use of cork as a biosorbent is a promising alternative for microextraction techniques associated with liquid and gas chromatography. In this study, a novel method was developed employing cork fiber for the determination of UV filters. Satisfactory results of 67 and $117 \%$ were obtained in the recovery assays ( $\mathrm{RSD} \leq 18 \%)$. The linear range of the proposed method is consistent with other results described in the literature. Added attractions of this method are that it does not require the use of solvents and cork is a renewable and natural product. Moreover, the method involving the use of cork as an SPME fiber is performed in only one stage for the isolation, extraction and concentration of the analytes.
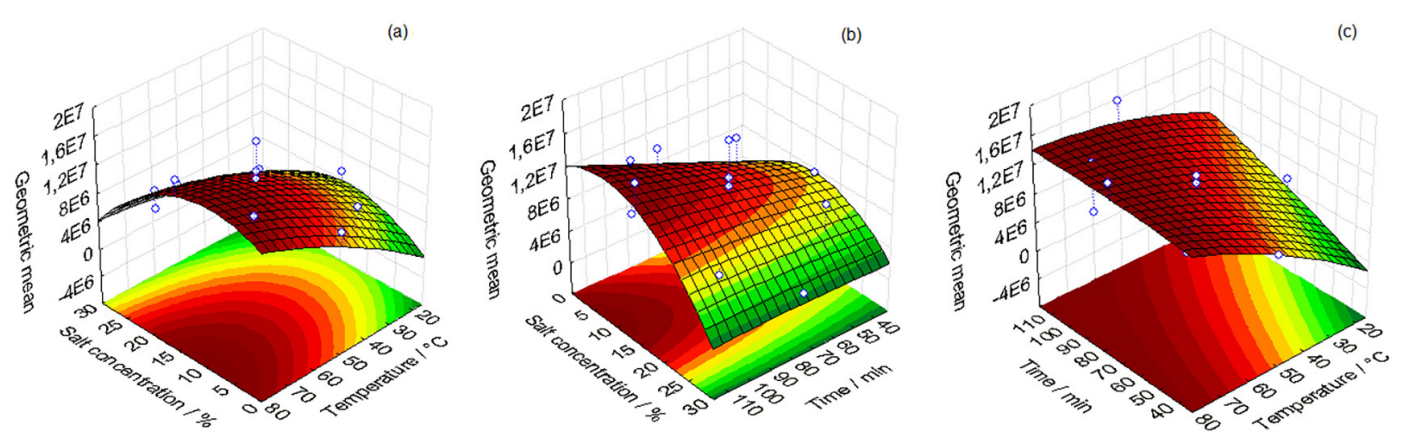

Figure 3. Response surfaces obtained from central composite design and the geometric mean of the peak areas, (a) temperature $v s$. time, (b) time $v s$. salt concentration and (c) temperature $v s$. salt concentration in the extraction of analytes by DI-SPME with cork fiber. 
Table 1. Validation parameters for method developed

\begin{tabular}{lccccc}
\hline Analyte & $\mathrm{LOD} /\left(\mu \mathrm{g} \mathrm{L}^{-1}\right)$ & $\left.\mathrm{LOQ} /(\mu \mathrm{g} \mathrm{L})^{-1}\right)$ & Linear range / $\left(\mu \mathrm{g} \mathrm{L}{ }^{-1}\right)$ & Calibration curve & $\mathrm{r}^{2}$ \\
\hline 4-MBC & 0.03 & 0.1 & $0.1-0.5$ & $\mathrm{y}=478795 \mathrm{x}+16827$ & 0.9829 \\
OD-PABA & 0.004 & 0.01 & $0.01-0.05$ & $\mathrm{y}=\left(3 \times 10^{6}\right) \mathrm{x}+7203.5$ & 0.9782 \\
\hline
\end{tabular}

4-MBC: 3-(4-methylbenzylidene)camphor; OD-PABA: 2-ethylhexyl 4-(dimethylamino)benzoate; LOD: limit of detection; LOQ: limit of quantification; $\mathrm{r}^{2}$ : linear correlation coefficient.

Table 2. Other validation parameters for developed method: precision and accuracy

\begin{tabular}{lccc}
\hline Analyte & Spiked level $/\left(\mu \mathrm{g} \mathrm{L}^{-1}\right)$ & Recovery / \% & RSD / \% \\
\hline \multirow{2}{*}{ 4-MBC } & 0.1 & 117 & 9 \\
& 0.4 & 107 & 18 \\
OD-PABA & 0.01 & 107 & 4 \\
& 0.04 & 67 & 3 \\
\hline
\end{tabular}

4-MBC: 3-(4-methylbenzylidene)camphor; OD-PABA: 2-ethylhexyl 4-(dimethylamino)benzoate; RSD: relative standard deviation.

Table 3. Comparison of the proposed method employing cork fiber with approaches described in the literature for the determination of UV filters in water samples

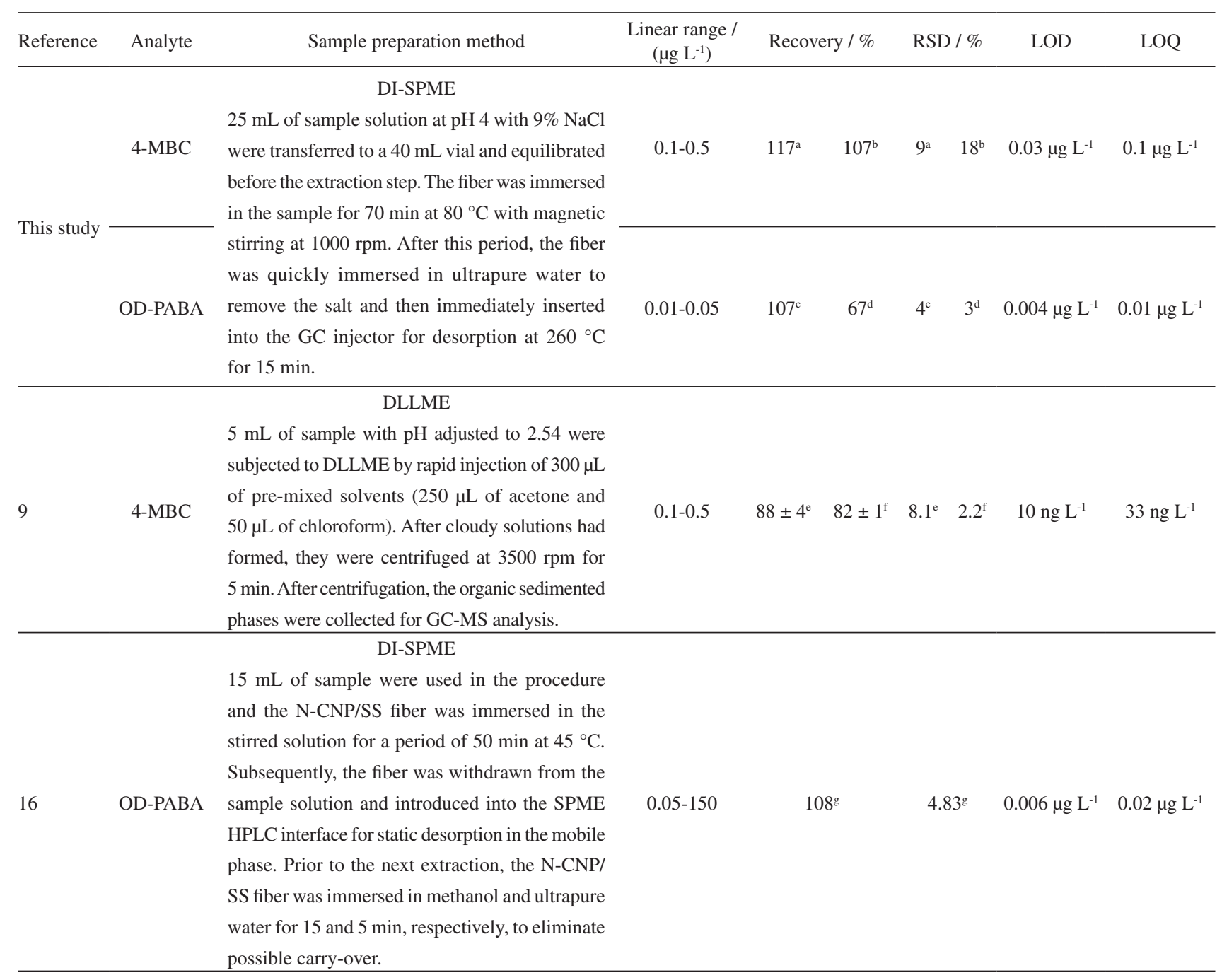


Table 3. Comparison of the proposed method employing cork fiber with approaches described in the literature for the determination of UV filters in water samples (cont.)

\begin{tabular}{|c|c|c|c|c|c|c|c|}
\hline Reference & Analyte & Sample preparation method & $\begin{array}{l}\text { Linear range / } \\
\qquad\left(\mu \mathrm{g} \mathrm{L}^{-1}\right)\end{array}$ & Recovery / \% & $\mathrm{RSD} / \%$ & LOD & LOQ \\
\hline 17 & OD-PABA & $\begin{array}{l}\text { DI-SPME } \\
\text { The extraction was carried out with } 15 \mathrm{~mL} \text { of } \\
\text { sample. The prepared fiber coated with } \mathrm{Zn}-\mathrm{ZnO} \\
\text { nanosheets was directly immersed in the sample } \\
\text { solution for } 40 \text { min at } 45^{\circ} \mathrm{C} \text {. After extraction, the } \\
\text { fiber was removed from the sample solution and } \\
\text { immediately introduced into the SPME HPLC } \\
\text { interface for static desorption in the mobile phase. } \\
\text { Between extractions, the fiber was immersed in } \\
\text { methanol and ultrapure water for } 10 \text { and } 5 \text { min, } \\
\text { respectively, to eliminate possible carry-over. }\end{array}$ & $0.1-200$ & $99.5^{\mathrm{g}}$ & $7.56^{\mathrm{g}}$ & $0.052 \mu \mathrm{g} \mathrm{L}^{-1}$ & - \\
\hline \multirow{2}{*}{13} & 4-MBC & \multirow{2}{*}{$\begin{array}{l}\text { SBSD } \mathrm{HE} \\
\text { A stir bar was placed in a vial and magnetically } \\
\text { stirred for } 10 \text { min at a high stirring rate to solvate } \\
\text { the nanoparticles. The MNP-coated stir bar was } \\
\text { then removed from the solution with clean plastic } \\
\text { tweezers, immersed in } 25 \mathrm{~mL} \text { of sample solution } \\
\text { adjusted to pH } 4 \text { with } 5 \% \mathrm{NaCl} \text { and then stirred } \\
\text { intensely for } 30 \text { min at room temperature. Upon } \\
\text { termination of the stirring process, nanoparticles } \\
\text { were magnetically collected on the stir bar. The } \\
\text { MNP-coated stir bar was then removed with clean } \\
\text { plastic tweezers and placed into a glass sample } \\
\text { tube for thermal desorption directly-coupled to } \\
\text { GC-MS. }\end{array}$} & $0.1-0.5$ & $97 \pm 9^{\mathrm{h}}$ & $8.6^{\mathrm{h}}$ & $23 \mathrm{ng} \mathrm{L}^{-1}$ & $78 \mathrm{ng} \mathrm{L}^{-1}$ \\
\hline & OD-PABA & & $0.1-0.5$ & $88 \pm 5^{h}$ & $4.4^{\mathrm{h}}$ & $30 \mathrm{ng} \mathrm{L}^{-1}$ & $99 \mathrm{ng} \mathrm{L}^{-1}$ \\
\hline
\end{tabular}

\section{DLLME}

$10 \mathrm{~g}$ of water sample at $\mathrm{pH}$ of 3 were subjected to DLLME by rapid injection of a mixture of $50 \mu \mathrm{L}$ of trichloroethane and $1000 \mu \mathrm{L}$ of acetone. The tube was then sealed and shaken gently by hand for $30 \mathrm{~s}$ and centrifuged at $3500 \times \mathrm{g}$ for $1 \mathrm{~min}$. A volume of $38 \mu \mathrm{L}$ of sediment was transferred to an amber vial and internal standard was added. This mixture was evaporated to dryness under a gentle stream of nitrogen. Lastly, the analytes were

OD-PABA silylated by addition of $40 \mu \mathrm{L}$ of BSTFA with $1 \%$ TMCS for $5 \mathrm{~min}$ in a domestic microwave $(600 \mathrm{~W})$ and, finally, $1 \mu \mathrm{L}$ of the extract was injected into the GC-MS system.

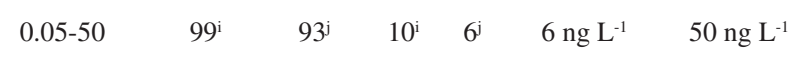

$\begin{array}{llllll}0.01-50 & 79^{\mathrm{i}} & 75^{\mathrm{j}} & 10^{\mathrm{i}} \quad 7^{\mathrm{j}} \quad 6 \mathrm{ng} \mathrm{L}^{-1} & 10 \mathrm{ng} \mathrm{L}^{-1}\end{array}$

In-syringe-MSA-DLLME-GC-MS system Method for online extraction, preconcentration, 4-MBC derivatization and chromatographic separation OD-PABA procedure, with simultaneous extraction and of UV filters. The cleaning of the syringes and manifold was carried out with acetone and ultrapure water. Thus, a possible carry-over was avoided. Optimum conditions: $350 \mu \mathrm{L}$ of trichloroethylene:BSTFA, $600 \mu \mathrm{L}$ of acetone volume and stirring time of $160 \mathrm{~s}$. The entire derivatization of the analytes and injection into

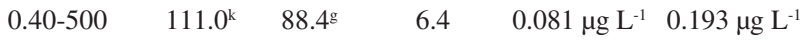

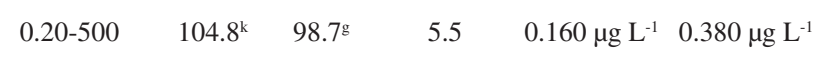
the GC-MS, was performed in 6 min.

4-MBC: 3-(4-methylbenzylidene)camphor; OD-PABA: 2-ethylhexyl 4-(dimethylamino)benzoate. Spiked concentrations: (a) $0.1 \mu \mathrm{g} \mathrm{L} \mathrm{L}^{-1}$, (b) $0.4 \mu \mathrm{gg} \mathrm{L}^{-1}$, (c) $0.01 \mu \mathrm{g} \mathrm{L}{ }^{-1}$, (d) $0.04 \mu \mathrm{g} \mathrm{L}^{-1}$, (e) $100 \mathrm{ng} \mathrm{L}^{-1}$, (f) $250 \mathrm{ng} \mathrm{L}^{-1}$, (g) $50 \mu \mathrm{g} \mathrm{L}^{-1}$, (h) $200 \mathrm{ng} \mathrm{L}^{-1}$, (i) $50 \mathrm{ng} \mathrm{L}^{-1}$, (j) $2500 \mathrm{ng} \mathrm{L}^{-1}$, and (k) $5 \mu \mathrm{g} \mathrm{L}{ }^{-1}$. DI-SPME: direct immersion solid-phase microextraction; DLLME: dispersive liquid-liquid microextraction; SBSD $\mu$ E: stir-bar sorptive-dispersive microextraction; in-syringe-MSA-DLLME: in-syringe magnetic stirring-assisted dispersive liquid-liquid microextraction; N-CNP/SS: nitrogen-containing carbon nanoparticle/ stainless steel; MNP: magnetic nanoparticles; BSTFA: $N, O$-bis(trimethylsilyl)trifluoroacetamide. 

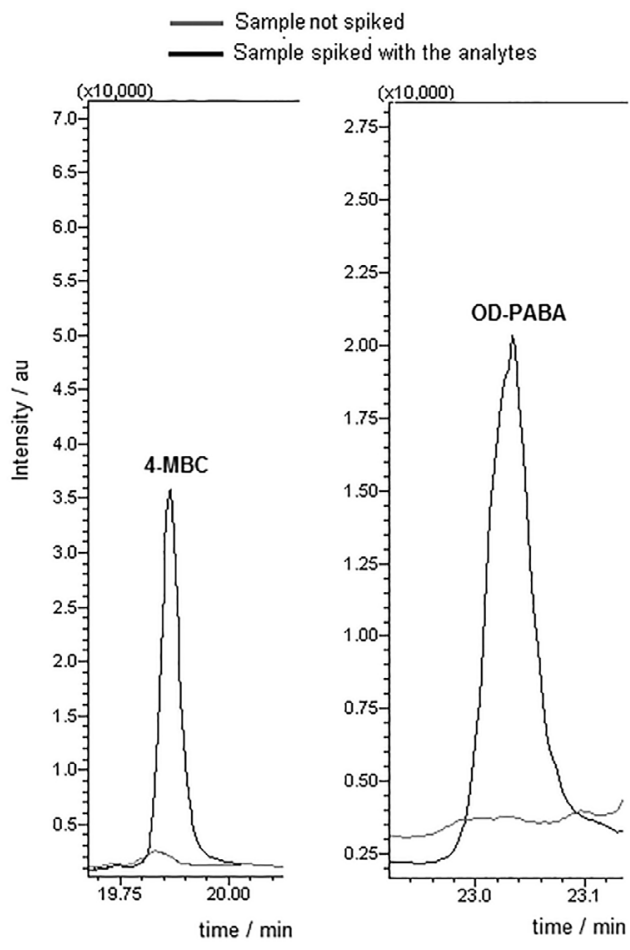

Figure 4. Chromatograms obtained after extraction by DI-SPME with cork fiber and determination by GC-MS. Black chromatogram: Quiriri River water sample spiked at $0.4 \mu \mathrm{g} \mathrm{L}^{-1}$ for 4-MBC and $0.04 \mu \mathrm{g} \mathrm{L}-1$ for OD-PAB. Gray chromatogram: unspiked Quiriri River water sample.

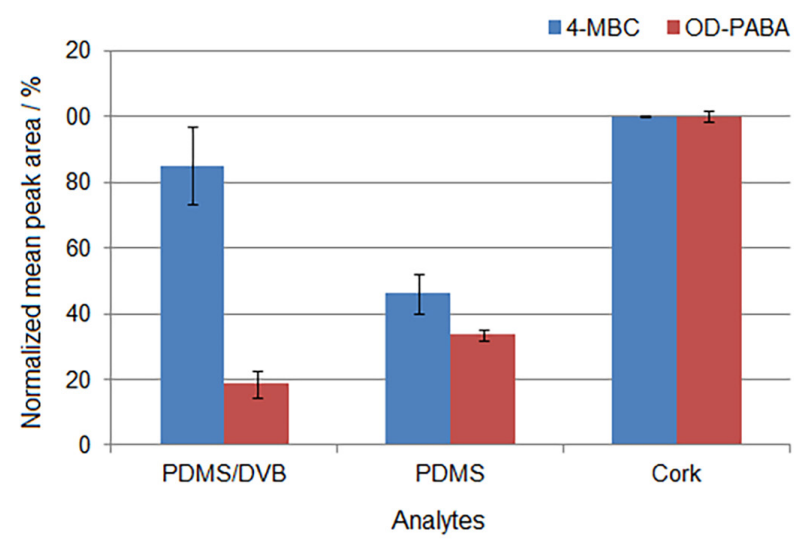

Figure 5. Comparison of extraction efficiencies of the cork fiber and of the PDMS/DVB and PDMS fibers for the extraction of 4-MBC and OD-PABA from water samples. DI-SPME conditions: spiked level $0.5 \mu \mathrm{g} \mathrm{L}{ }^{-1}$, extraction time $70 \mathrm{~min}$, extraction temperature $80^{\circ} \mathrm{C}, 9 \% \mathrm{NaCl}$, sample $\mathrm{pH} 4$ and 3 replicates.

\section{Supplementary Information}

Supplementary data are available free of charge at http://jbcs.sbq.org.br as PDF file.

\section{Acknowledgments}

The authors are grateful to the Brazilian Government Agency Conselho Nacional de Desenvolvimento Científico e Tecnológico (CNPq) for the financial support which made this research possible.

\section{References}

1. Kim, K.; Mueller, J.; Park, Y.-B.; Jung, H.-R.; Kang, S.-H.; Yoon, M.-H.; Lee, J.-B.; J. Chromatogr. Sci. 2011, 49, 554.

2. Wharton, M.; Geary, M.; O'Connor, N.; Curtin, L.; Ketcher, K.; J. Chromatogr. Sci. 2015, 53, 1289.

3. Dias, A. N.; Silva, A. C.; Simão, V.; Merib, J.; Carasek, E.; Anal. Chim. Acta 2015, 888, 59.

4. Zhang, H.; Lee, H. K.; Anal. Chim. Acta 2012, 742, 67.

5. Tovar-Sánchez, A.; Sánchez-Quiles, D.; Basterretxea, G.; Benedé, J. L.; Chisvert, A.; Salvador, A.; Moreno-Garrido, I.; Blasco, J.; PLoS One 2013, 8, e65451.

6. Pedrouzo, M.; Borrull, F.; Marce, R. M.; Pocurull, E.; TrAC, Trends Anal. Chem. 2011, 30, 749.

7. Vila, M.; Lamas, J. P.; Garcia-Jares, C.; Dagnac, T.; Llompart, M.; Microchem. J. 2016, 124, 530.

8. Magi, E.; Scapolla, C.; Di Carro, M.; Rivaro, P.; Nguyen, K. T. N.; Anal. Methods 2013, 5, 428.

9. Benedé, J. L.; Chisvert, A.; Salvador, A.; Sánchez-Quiles, D.; Tovar-Sánchez, A.; Anal. Chim. Acta 2014, 812, 50.

10. Cunha, S. C.; Pena, A.; Fernandes, J. O.; J. Chromatogr. A 2015, 1414, 10.

11. Clavijo, S.; Avivar, J.; Suárez, R.; Cerdà; V.; J. Chromatogr. A 2016, 1443, 26.

12. Pintado-Herrera, M. G.; González-Mazo, E.; Lara-Martín, P. A.; Anal. Chim. Acta 2014, 851, 1.

13. Benedé, J. L.; Chisvert, A.; Giokas, D. L.; Salvador, A.; Talanta 2016, 147, 246.

14. Benedé, J. L.; Chisvert, A.; Giokas, D. L.; Salvador, A.; J. Chromatogr. A 2014, 1362, 25.

15. Li, L.; Guo, R.; Li, Y.; Guo, M.; Wang, X.; Du, X.; Anal. Chim. Acta 2015, 867, 38.

16. Wang, T.-E.; Guo, M.; Song, W.-L.; Zhang, Y.-D.; Du, X.-Z.; Anal. Methods 2015, 7, 3385.

17. Song, W.; Guo, M.; Zhang, Y.; Zhang, M.; Wang, X.; Du, X.; J. Chromatogr. A 2015, 1384, 28.

18. Sambandan, D. R.; Ratner, D.; J. Am. Acad. Dermatol. 2011, 64, 748

19. Dias, A. N.; Simão, V.; Merib, J.; Carasek, E.; Anal. Chim. Acta 2013, 772, 33.

20. Dias, A. N.; Simão, V.; Merib, J.; Carasek, E.; Talanta 2015, 13, 409.

21. Pereira, H.; Wood Sci. Technol. 1992, 26, 259.

22. Olivella, M. A.; Fernández, I.; Cano, L.; Jové, P.; Oliveras, A.; Int. J. Environ. Res. 2013, 7, 225.

Submitted: February 23, 2017

Published online: May 17, 2017 